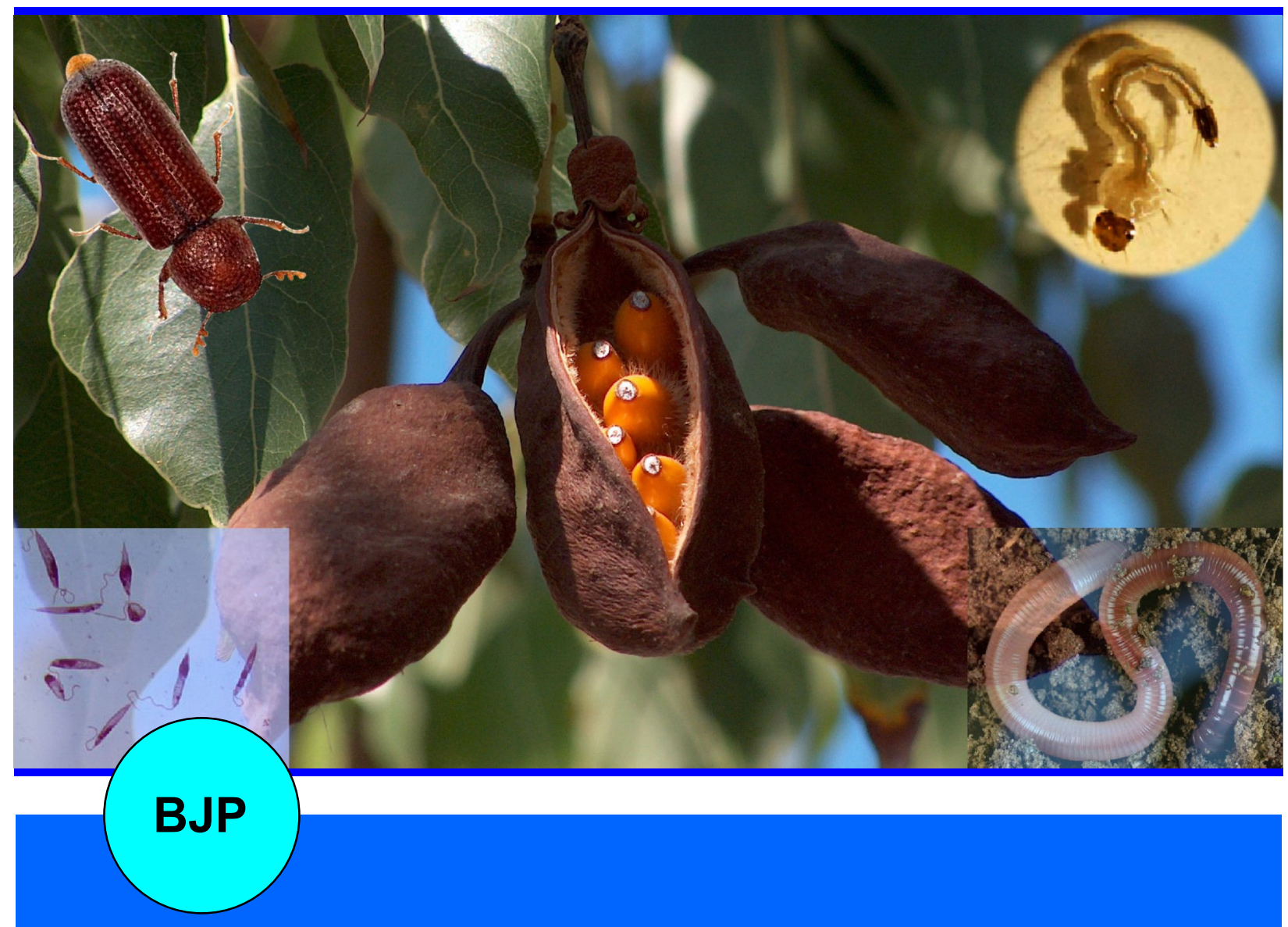

Bangladesh Journal of Pharmacology

Research Article

Larvicidal, leishmanicidal, insecticidal and anthelmintic effects of Sterculia diversifolia stem bark and leaf 


\section{Larvicidal, leishmanicidal, insecticidal and anthelmintic effects of Sterculia diversifolia stem bark and leaf}

Fazle Rabbi, Amir Zada and Amna Nisar

Department of Pharmacy, University of Peshawar, Peshawar, Khyber Pakhtunkhwa, Pakistan.

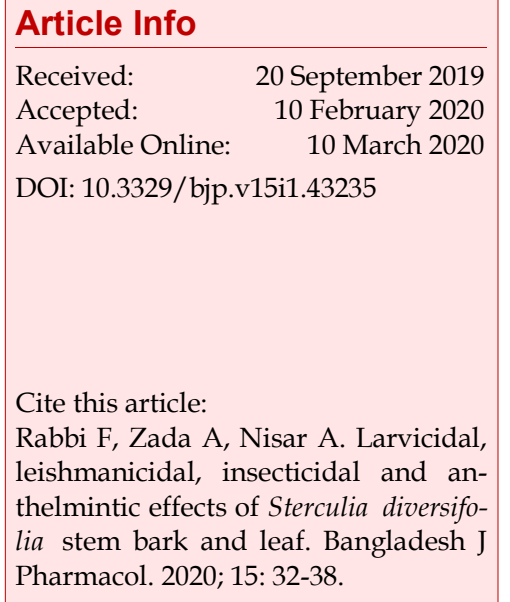

\section{Abstract}

The present study was conducted to evaluate the stem bark and leaf of Sterculia diversifolia for larvicidal, leishmanicidal, insecticidal and anthelmintic activities. In the larvicidal activity, dichloromethane and ethyl acetate fractions of both stem bark and leaf showed significant results, while the ethyl acetate fraction showed mild activity $\left(\mathrm{IC}_{50}: 70.09 \pm 0.09 \mu \mathrm{g} / \mathrm{mL} ; 71.25 \pm 0.01\right.$ $\mu \mathrm{g} / \mathrm{mL}$ ). In the insecticidal activity of the stem bark, $n$-hexane fraction showed mild activity (20-40\% mortality) against all three subjects, while the insecticidal activity of leaf, methanolic extract and $n$-hexane fractions showed moderate activity (60\% mortality) against Rhyzopertha dominica and Callosobruchus analis. In the anthelmintic activity of stem bark and leaf, ethyl acetate fraction exhibited activity in a dose-dependent manner giving time of paralysis and death shorter followed by dichloromethane fraction with 200 $\mathrm{mg} / \mathrm{mL}$ concentration. Hence, it is clear that S. diversifolia stem bark and leaf possess larvicidal, leishmanicidal, insecticidal and anthelmintic agents.

\section{Introduction}

Extensive research on medicinal plants is highly desired to discovered convenient therapeutic moieties that are less toxic, highly potent and effective in case of resistant pathological conditions. Recently various plants reported larvicidal [Garcinia mangostana (Sasikumar and Ghosh, 2017), Zingiber officinale (Rahuman et al., 2008)], leishmanicidal [Tunisian terrestris (Bouabdallah et al., 2018)], insecticidal and anthelmintic [Coriandrum sativum (Hosseinzadeh et al., 2016), Viola betonicifolia (Rizwan et al., 2019)] effects.

Amongst medicinal plants, family Sterculiaceae is a source of bioactive compounds of different chemical classes such as alkaloids, glycosides, terpenoids, sterols, steroids, saponins, apigenins, flavonoids, polyphenols, essential oils, tannins, carbohydrates, proteins, triterpenes and reducing sugars (Khatiashvili et al., 2007; Ouédraogo et al., 2013). The genus Sterculia also possess various types of biological activities such as $S$. vallosa bears anthelmintic and leishmanicidal activities while $S$. guttata and $S$. foetida bears larvicidal and insecticidal activities respectively (Das et al., 2017; Alam et al., 2012; Katade et al., 2006; Rani et al., 2010). S. diversifolia has antibacterial, antifungal and antioxidant activity. In earlier study, few fatty acid constituents were isolated from the S. diversifolia (Salem et al., 2014). The present study was designed to investigate the larvicidal, leishmanicidal, insecticidal and anthelmintic activity of methanolic extract of $S$. diversifolia stem bark and leaf and their fractions.

\section{Materials and Methods}

\section{Plant material}

Plant materials (stem bark and leaf) were collected from the botanical garden of Pakistan Forest Institute $\left(34^{\circ}\right.$ 
00'50.6"N 71²9'03.0"E), University of Peshawar, Pakistan, in September, 2014. The identification of the plant was done a taxonomist Mr. Ghulam Jelani at the Department of Botany, University of Peshawar. Under the reference No: Bot.20098, a specimen was deposited in the above-mentioned institute herbarium.

\section{Extraction and fractionation}

S. diversifolia stem bark (17 kg) and leaf (13 kg) were dried completely in shade at room temperature. These parts were then crushed to powder and macerated with 90\%hydro-methanolic solvent for two weeks. After maceration, the filtration was conducted with Whatman filter paper No. 1. The obtained crude extracts were concentrated under a reduced pressure at $40^{\circ} \mathrm{C}$ using a rotary evaporator (R-1001-V, Zhengzhou Great Wall Scientific Industrial and Trade Co., China) (Rabbi et al., 2017). The methanolic extract of stem bark and leaf was obtained in $950 \mathrm{~g}$ and $1.2 \mathrm{~kg}$ quantity respectively. The extract was mixed with distilled water $(2.5 \mathrm{~L})$ and soaked overnight. Fractionation was conducted with various organic solvents i.e. $n$-hexane $(3 \times 5 \mathrm{~L})$, dichloromethane $(3 \times 5 \mathrm{~L})$, ethyl acetate $(3 \times 5 \mathrm{~L})$ and $n$-butanol $(3 \times 5 \mathrm{~L})$. The remaining was considered as watersoluble fraction i.e. aqueous fraction.

\section{Larvicidal activity}

The larvicidal activity of the crude methanolic extract and its fractions of both stem bark and leaf were screened according to the protocol recommended by the WHO (1981). Various concentrations (25, 50, 100, 250, $500 \mathrm{ppm})$ of the test samples were used. All the extracts were dissolved in respective solvents. A glass beaker of $500 \mathrm{~mL}$ was used containing $250 \mathrm{~mL}$ tap water. Early third instar of Aedes aegypti (25) was introduced to each of the test solutions as well as the control. In the case of control, methanol was only used. Six replicates were maintained at a time for each experiment. The $\mathrm{LC}_{50}$ was calculated using GraphPad prism 5 software (Bucker et

\section{Box 1: Anthelmintic activity}

\section{Principle}

The anthelmintic assay of crude methanolic extract and various fractions of both stem bark and leaf were evaluated on adult earthworms (Pheretima posthuma) due to its anatomical and physiological resemblance with the intestinal roundworm parasites of human beings

\section{Requirements}

Albendazole, Earthworm (length: 3-5 cm; width: 0.1-0.2 cm), Extract; Normal saline, Stopwatch

\section{Procedure}

Step 1: Earthworms were collected from the moist soil and then washed with normal saline for the removal of the adhering dirt

Step 2: Three earthworms were released in each glass beaker al., 2013).

\section{Leishmanicidal activity}

The crude extract of $S$. diversifolia (stem bark and leaf), and its subsequent fractions were screened for antileishmanial activity using Leishmania major. NNN biphasic medium was used in which promastigotes of Leishmania were grown. This medium was modified earlier and normal physiological saline was used for this purpose. For culturing parasite, the RPMI medium (1640 Sigma) was used. Inactivated fetal bovine serum (10\%) was also supplemented to the medium. Leishmania major parasites were harvested at log phase of growth and centrifuged for $10 \mathrm{~min}$ at 3,000 rpm. Parasites were washed three times with normal saline maintaining the same experimental conditions. With the addition of freshly prepared culture medium, final density (106 cells $/ \mathrm{mL}$ ) of parasites was achieved. About $20 \mu \mathrm{L}$ test sample and $180 \mu \mathrm{L}$ medium were added to each well of 96-well microplate and then serially diluted. $100 \mu \mathrm{L}$ prepared culture of Leishmania was added to all wells. One row containing only media and Leishmania culture was served as negative control while the second row served as positive control con-taining pentamidine and amphotericin B. The number of living parasites was counted microscopically after incubation for 72 hours at $22^{\circ} \mathrm{C}$ using Neubauer counting chamber. Ezfit 5.03 software was used for the determination of $\mathrm{IC}_{50}$ value (Ali et al., 2016).

\section{Insecticidal activity}

The crude methanolic extracts (stem bark and leaf) and their various fractions were studied for insecticidal activity against Tribolium castaneum, Rhyzopertha dominica and Callosobruchus analis. Insecticidal assay of crude methanolic extracts (stem bark, leaf) and their fractions were assessed by using the impregnated filter paper method (direct contact method). In this method, $T$. castaneum, $R$. dominica and $C$. analis were reared under

containing solution $(50 \mathrm{~mL})$ of reference drug albendazole and extract $(50,100$ and $200 \mathrm{mg} / \mathrm{mL}$ each) in distilled water.

Step 3: Distilled water was served as negative control.

Step 4: The time taken to paralysis and death of earthworm was observed and noted.

Notes

The earthworms were authenticated by Mr. Abdur Rahim, an expert in animals taxonomy.

When the earthworms did not revive in the normal saline, it indicated water paralysis, while the earthworms lost their motility followed by fading away of their body color or even not moved when dipped in $50^{\circ} \mathrm{C}$ hot water concluded the death of animals.

\section{References}

Panda et al., 2015 


\begin{tabular}{|c|c|c|c|c|c|c|}
\hline \multicolumn{7}{|c|}{ Table I } \\
\hline \multicolumn{7}{|c|}{ Larvicidal activity of methanol extract and its fractions } \\
\hline \multirow[t]{2}{*}{ Test sample } & \multicolumn{5}{|c|}{ \%Mortality \pm S.D } & \multirow{2}{*}{$\begin{array}{l}\mathrm{LC}_{50} \\
\mathrm{ppm}\end{array}$} \\
\hline & $25 \mathrm{ppm}$ & $50 \mathrm{ppm}$ & $100 \mathrm{ppm}$ & $250 \mathrm{ppm}$ & $500 \mathrm{ppm}$ & \\
\hline \multicolumn{7}{|l|}{ Stem bark } \\
\hline Methanol & $22.2 \pm 1.0$ & $26.5 \pm 1.2$ & $38.2 \pm 0.8$ & $42.4 \pm 1.0$ & $52.5 \pm 0.4$ & 66.0 \\
\hline$n$-Hexane & $8.4 \pm 1.8$ & $10.8 \pm 1.0$ & $16.0 \pm 1.6$ & $18.3 \pm 0.4$ & $22.1 \pm 0.8$ & 326.5 \\
\hline Dichloromethane & $45.6 \pm 1.2$ & $48.8 \pm 0.4$ & $56.9 \pm 0.2$ & $70.2 \pm 0.2$ & $82.6 \pm 1.8$ & 28.7 \\
\hline Ethyl acetate & $42.9 \pm 0.8$ & $52.5 \pm 0.6$ & $60.5 \pm 1.6$ & $70.2 \pm 0.2$ & $81.8 \pm 1.4$ & 31.5 \\
\hline$n$-Butanol & $06.0 \pm 0.2$ & $09.2 \pm 1.8$ & $12.6 \pm 1.0$ & $15.8 \pm 0.6$ & $19.3 \pm 1.2$ & 353.2 \\
\hline Aqueous & $06.0 \pm 0.8$ & $06.9 \pm 0.2$ & $07.3 \pm 1.8$ & $09.4 \pm 0.8$ & $12.2 \pm 1.4$ & -- \\
\hline Control & -- & -- & -- & -- & $2.2 \pm 0.8$ & -- \\
\hline \multicolumn{7}{|l|}{ Leaf } \\
\hline Methanol & $28.4 \pm 0.2$ & $32.8 \pm 0.8$ & $39.5 \pm 0.0$ & $46.2 \pm 0.4$ & $54.2 \pm 0.6$ & 64.2 \\
\hline$n$-Hexane & $6.2 \pm 1.2$ & $9.0 \pm 0.0$ & $9.8 \pm 0.8$ & $11.3 \pm 0.6$ & $14.0 \pm 1.8$ & 399.2 \\
\hline Dichloromethane & $48.6 \pm 0.8$ & $54.9 \pm 0.8$ & $59.1 \pm 0.4$ & $72.1 \pm 1.8$ & $88.1 \pm 1.4$ & 12.0 \\
\hline Ethyl acetate & $46.3 \pm 1.2$ & $53.6 \pm 1.6$ & $58.2 \pm 0.6$ & $70.0 \pm 1.2$ & $87.4 \pm 1.6$ & 14.4 \\
\hline$n$-Butanol & $07.9 \pm 0.4$ & $08.2 \pm 1.0$ & $12.0 \pm 1.2$ & $14.8 \pm 0.2$ & $17.2 \pm 0.8$ & 371.8 \\
\hline Aqueous & $04.2 \pm 0.6$ & $05.2 \pm 0.4$ & $07.2 \pm 1.4$ & $09.5 \pm 1.0$ & $12.9 \pm 0.2$ & -- \\
\hline Control & -- & -- & -- & -- & $2.2 \pm 0.8$ & -- \\
\hline
\end{tabular}

controlled and specific conditions of humidity and temperature in the laboratory. Those insects were selected which are uniform in size and age. The test sample (200 $\mathrm{mg}$ ) was dissolved in acetone $(3 \mathrm{~mL})$ to prepare the stock solution. In petri dish, filter paper $(90 \mathrm{~mm})$ was placed and then it was loaded with the test sample $\left(1019.1 \mu \mathrm{g} / \mathrm{cm}^{2}\right)$. The volatile organic solvent was evaporated after 24 hours. Ten active insects were transferred to the next day to each petri dish with the help of a brush and incubated for 24 hours $\left(27 \pm 1^{\circ} \mathrm{C}\right)$ with $50 \%$ humidity in the growth chamber. Acetone and permethrin $\left(239.50 \mu \mathrm{g} / \mathrm{cm}^{2}\right)$ were used as negative and positive control respectively. The percent mortality was determined by comparing the test sample with the positive control (Saeed et al., 2010). It was determined by counting the number of survived insects as below:

$$
\% \text { Mortality }=100-\frac{\text { Number of insects alive in test }}{\text { Number of insects alive in control }} \times 100
$$

\section{Results}

\section{Larvicidal activity}

The maximum activity was shown by dichloromethane and ethyl acetate fractions of stem bark (Table I). The dichloromethane fraction exhibited 45.6, 48.8, 56.9, 70.2 and $82.6 \%$ mortality at the test doses of 25, 50, 100, 250 and $500 \mathrm{ppm}$ respectively. Ethyl acetate fraction showed \% mortality of $42.9,52.5,60.5,70.2$ and $81.8 \%$ at the same concentrations. The methanolic extract show- ed mortality of $22.2,26.5,38.2,42.4$ and $52.5 \%$ at the same concentrations respectively. Other fractions did not show significant activity. The maximum activity of stem bark was observed against dichloromethane fraction followed by ethyl acetate, methanolic extract, $n$ hexane, $n$-butanol and aqueous fractions with $\mathrm{LC}_{50}$ values 28.7, 31.5, 66.0, 326.5 and $353.2 \mu \mathrm{g} / \mathrm{mL}$ respecttively.

Dichloromethane and ethyl acetate fractions of leaf showed the maximum activity. Dichloromethane fraction exhibited 48.6, 54.9, 59.1, 72.1 and $88.1 \%$ mortality at the test doses of 25, 50, 100, 250 and 500 ppm respectively. Ethyl acetate fraction showed mortality of

\begin{tabular}{|c|c|c|}
\hline \multicolumn{3}{|c|}{$\begin{array}{l}\text { Leishmanicidal activity of methanol extract and its } \\
\text { fractions }\end{array}$} \\
\hline Test sample & $\begin{array}{c}\text { Stem bark } \\
\text { IC }_{50}(\mu \mathrm{g} / \mathrm{mL}) \\
\pm \text { S.D }\end{array}$ & $\begin{array}{c}\text { Leaf } \\
\text { IC }_{50}(\mu \mathrm{g} / \mathrm{mL}) \\
\pm \text { S.D }\end{array}$ \\
\hline Methanol & $>100$ & $>100$ \\
\hline$n$-Hexane & $77.3 \pm 0.3$ & $>100$ \\
\hline Dichloromethane & $79.3 \pm 0.0$ & $79.3 \pm 0.1$ \\
\hline Ethyl acetate & $70.1 \pm 0.1$ & $71.3 \pm 0.0$ \\
\hline$n$-Butanol & $>100$ & $>100$ \\
\hline Aqueous & $>100$ & $>100$ \\
\hline Amphotericin-B & $0.3 \pm 0.1$ & $0.3 \pm 0.1$ \\
\hline Pentamidine & $5.1 \pm 0.1$ & $5.1 \pm 0.1$ \\
\hline
\end{tabular}

Table II 
Table III

Insecticidal activity of methanolic extract and its fractions ( $\%$ Mortality)

\begin{tabular}{|lcccccc|}
\hline \multirow{2}{*}{ Test sample } & \multicolumn{2}{c}{ Tribolium castaneum } & \multicolumn{2}{c|}{ Rhyzopertha dominica } & \multicolumn{2}{c|}{ Callosobruchus analis } \\
\cline { 2 - 7 } & Stem bark & Leaf & Stem bark & Leaf & Stem bark & Leaf \\
\hline Methanol & 20 & - & - & 60 & - & - \\
$n$-Hexane & 40 & - & 20 & - & 30 & 60 \\
Dichloromethane & - & - & - & - & - & 10 \\
Ethyl acetate & - & - & - & - & - & 10 \\
$n$-Butanol & - & - & - & - & - & 10 \\
Aqueous & - & - & 100 & 100 & 100 & 100 \\
Positive control & 100 & 100 & - & - & - \\
(permethrin) & - & - & - & & - \\
Negative control & - & - & & & - \\
\hline
\end{tabular}

$46.3,53.6,58.2,70.0$ and $87.4 \%$ at the same concentrations. The methanolic extract also showed mortality of $28.4,32.8,39.5,46.2$ and $54.2 \%$ at the same concentrations. The maximum activity of leaf was observed against dichloromethane fraction followed by ethyl acetate, methanolic extract, $n$-butanol and n-hexane with $\mathrm{LC}_{50}$ values 12.0, 14.4, 64.2, 371.8 and $399.2 \mu \mathrm{g} / \mathrm{mL}$ (Table I).

\section{Leishmanicidal activity}

The leishmanicidal activity of the crude methanolic extract and its fractions of stem bark and leaf were evaluated against promastigotes of Leishmania major (Table II). In the leishmanicidal activity of stem bark, ethyl acetate fraction showed mild activity $\left(\mathrm{IC}_{50}: 70.1\right.$ $\mu \mathrm{g} / \mathrm{mL}$ ) followed by $n$-hexane fraction ( $\mathrm{IC}_{50}: 77.3 \mu \mathrm{g} /$ $\mathrm{mL}$ ). In the leishmanicidal activity of leaf, ethyl acetate fraction showed mild activity ( $\mathrm{IC}_{50}: 71.3 \mu \mathrm{g} / \mathrm{mL}$ ) followed by dichloromethane fraction $\left(\mathrm{IC}_{50}: 79.3 \mu \mathrm{g} / \mathrm{mL}\right)$.

\section{Insecticidal activity}

The insecticidal activity of crude methanolic extract and its fractions were studied against $R$. dominica, T. castaneum and $C$. analis. The results revealed that the crude methanolic extract stem bark showed low insecticidal activity (20\%) against T. castaneum and inactive against rest of the insects (Table III). The $n$-hexane fraction showed good activity, $40 \%$ against R. dominica, 20\% against T. castaneum and $30 \%$ against C. analis. Other fractions; dichloromethane, ethyl acetate, $n$-butanol and aqueous were found inactive against test insects. In case of leaf, crude methanolic extract showed good insecticidal activity $(60 \%)$ against $R$. dominica and inactive against the rest of the insects. Other fractions; $n$-hexane, dichloromethane, ethyl acetate, $n$-butanol and aqueous showed $60,10,10,20,10 \%$ insecticidal activity respectively against $C$. analis, while were found inactive against $R$. dominica, $T$. castaneum.

\section{Anthelmintic activity}

In the anthelmintic activity, extract of $S$. diversifolia (stem bark and leaf) and its fractions demonstrated worms paralysis as well as death as presented in Table IV. The extracts in higher concentrations produced much earlier paralytic effect and shorten the time to death for all worms. Ethyl acetate fraction exhibited anthelmintic activity in dose-dependent manner giving time of paralysis and death shorter followed by dichloromethane fraction with $200 \mathrm{mg} / \mathrm{mL}$ concentration. The crude methanolic extract and aqueous fraction exhibited moderate anthelmintic activity, paralyzed worm after 57.5 and $65.9 \mathrm{~min}$, while killed after 72.7 and $78.3 \mathrm{~min}$ respectively at the tested dose of $200 \mathrm{mg} /$ $\mathrm{mL}$. The $n$-hexane and $n$-butanol fractions showed mild activity and paralyzed the worm after 62.4 and $80.6 \mathrm{~min}$ while killed after 82.6 and $91.6 \mathrm{~min}$ respectively at the test dose of $200 \mathrm{mg} / \mathrm{mL}$. The ethyl acetate and dichloromethane fractions of leaf showed good activity and paralyzed the worm after 23.1 and $28.3 \mathrm{~min}$ while killed after 39.7 and 54.9 min respectively at the tested dose of $200 \mathrm{mg} / \mathrm{mL}$. crude methanolic extract and $n$-hexane fraction of leaf exhibit moderate anthelmintic activity paralyzed worm after 59.4 and $60.5 \mathrm{~min}$, while killed after 75.2 and 77.6 min respectively at the tested dose of $200 \mathrm{mg} / \mathrm{mL}$. Aqueous and $n$-butanol fractions of leaf exhibit mild activity and paralyzed worm after 70.5 and $72.3 \mathrm{~min}$ while killed after 87.4 and $89.5 \mathrm{~min}$ respectively at the dose of $200 \mathrm{mg} / \mathrm{mL}$. The value of paralysis and death for albendazole (standard) was 0.8 and 4.2 min respectively.

\section{Discussion}

Larvicidal, leishmanicidal, insecticidal and anthelmintic activities are reported for the first time in this work. Keeping in view the importance of the larvicidal activity of stem bark and leaf, maximum activity was shown by dichloromethane (28.7 and $12.0 \mathrm{ppm})$ followed by ethyl acetate ( 31.5 and $14.4 \mathrm{ppm})$ fractions. Results indicated the potency of leaf fractions over stem bark fractions. In the leishmanicidal activity, maximum 


\begin{tabular}{|c|c|c|c|c|c|}
\hline \multicolumn{6}{|c|}{ Table IV } \\
\hline \multicolumn{6}{|c|}{ Anthelmintic activity of methanolic extract and its fractions } \\
\hline \multirow[t]{2}{*}{ Test sample } & \multicolumn{3}{|c|}{ Stem bark } & \multicolumn{2}{|c|}{ Leaf } \\
\hline & $\begin{array}{c}\text { Conc. } \\
(\mathrm{mg} / \mathrm{mL})\end{array}$ & $\begin{array}{l}\text { Time taken for paral- } \\
\text { ysis (min) }\end{array}$ & $\begin{array}{l}\text { Time taken for } \\
\text { death (min) }\end{array}$ & $\begin{array}{l}\text { Time taken for } \\
\text { paralysis (min) }\end{array}$ & $\begin{array}{l}\text { Time taken for } \\
\text { death (min) }\end{array}$ \\
\hline \multirow[t]{3}{*}{ Methanol } & 50 & $66.3 \pm 0.8$ & $84.2 \pm 1.3$ & $70.2 \pm 1.0$ & $87.3 \pm 0.4$ \\
\hline & 100 & $62.5 \pm 1.1$ & $78.7 \pm 1.0$ & $65.9 \pm 2.4$ & $81.5 \pm 3.1$ \\
\hline & 200 & $57.5 \pm 2.2$ & $72.7 \pm 3.1$ & $59.4 \pm 1.9$ & $75.2 \pm 0.3$ \\
\hline \multirow[t]{3}{*}{ n-Hexane } & 50 & $70.9 \pm 1.4$ & $93.8 \pm 0.8$ & $68.3 \pm 2.9$ & $87.2 \pm 2.2$ \\
\hline & 100 & $68.1 \pm 1.9$ & $88.6 \pm 2.9$ & $64.0 \pm 0.6$ & $80.3 \pm 1.1$ \\
\hline & 200 & $62.4 \pm 3.1$ & $82.6 \pm 2.7$ & $60.5 \pm 0.3$ & $77.6 \pm 2.3$ \\
\hline \multirow[t]{3}{*}{ Dichloromethane } & 50 & $50.3 \pm 1.0$ & $89.6 \pm 2.7$ & $48.3 \pm 3.0$ & $82.4 \pm 0.4$ \\
\hline & 100 & $40.4 \pm 2.5$ & $68.3 \pm 0.6$ & $38.1 \pm 1.6$ & $62.8 \pm 1.5$ \\
\hline & 200 & $31.2 \pm 2.0$ & $60.0 \pm 0.9$ & $28.3 \pm 2.2$ & $54.9 \pm 2.7$ \\
\hline \multirow[t]{3}{*}{ Ethyl acetate } & 50 & $45.2 \pm 0.5$ & $70.6 \pm 3.0$ & $42.7 \pm 1.2$ & $67.3 \pm 1.3$ \\
\hline & 100 & $32.7 \pm 1.8$ & $59.8 \pm 2.7$ & $31.1 \pm 2.1$ & $50.6 \pm 0.7$ \\
\hline & 200 & $24.8 \pm 2.7$ & $41.8 \pm 0.2$ & $23.1 \pm 1.1$ & $39.7 \pm 2.9$ \\
\hline \multirow[t]{3}{*}{$n$-Butanol } & 50 & $102.4 \pm 0.5$ & $123.7 \pm 1.5$ & $100.8 \pm 3.0$ & $121.0 \pm 0.8$ \\
\hline & 100 & $88.8 \pm 3.2$ & $102.3 \pm 2.2$ & $81.8 \pm 0.7$ & $99.5 \pm 1.5$ \\
\hline & 200 & $80.6 \pm 0.7$ & $91.6 \pm 1.2$ & $72.3 \pm 1.5$ & $89.5 \pm 2.7$ \\
\hline \multirow[t]{3}{*}{ Aqueous } & 50 & $91.4 \pm 1.2$ & $112.7 \pm 0.5$ & $93.7 \pm 1.6$ & $117.5 \pm 0.5$ \\
\hline & 100 & $80.4 \pm 3.2$ & $98.4 \pm 2.5$ & $85.0 \pm 2.7$ & $101.7 \pm 2.9$ \\
\hline & 200 & $65.9 \pm 1.7$ & $78.3 \pm 1.0$ & $70.5 \pm 1.4$ & $87.4 \pm 1.0$ \\
\hline $\begin{array}{l}\text { Negative control ( } 1 \% \\
\text { carboxymethyl cellulose } \\
\text { in normal saline) }\end{array}$ & -- & -- & -- & -- & -- \\
\hline \multirow{3}{*}{$\begin{array}{l}\text { Positive control } \\
\text { (albendazole) }\end{array}$} & 50 & $1.8 \pm 0.5$ & $7.3 \pm 2.0$ & $1.8 \pm 0.5$ & $7.3 \pm 2.0$ \\
\hline & 100 & $1.2 \pm 1.7$ & $5.2 \pm 1.0$ & $1.2 \pm 1.7$ & $5.2 \pm 1.0$ \\
\hline & 200 & $0.8 \pm 0.2$ & $4.2 \pm 0.2$ & $0.8 \pm 0.2$ & $4.2 \pm 0.2$ \\
\hline
\end{tabular}

activity was observed for ethyl acetate fraction ( $\mathrm{IC}_{50}$ $70.1 \mu \mathrm{g} / \mathrm{mL}$ and $71.3 \mu \mathrm{g} / \mathrm{mL}$ respectively) amongst test samples of Sterculia diversifolia stem bark and leaf showing almost similar results. The results of insecticidal activity reveal that methanolic extract of stem bark, $n$-hexane fraction showed mild to moderate activity (percent mortality) against all three insects followed by crude methanolic extract, while the insecticidal activity of leaf, none of the fraction showed insecticidal activity against all three insects, however, the methanolic extract showed $60 \%$ mortality against Rhyzopertha dominica while $n$-hexane fraction showed $60 \%$ activity against Callosobruchus analis. In anthelmintic activity of stem bark and leaf, ethyl acetate fraction exhibited activity in dose-dependent manner giving time of paralysis and death shorter followed by dichloromethane fraction with the highest concentration (200 $\mathrm{mg} / \mathrm{mL}$ ), showing almost comparable outcomes.

Crude extracts are a complex mixture of active compounds (Anees, 2008). Various extracts possess larvi- cidal activity against mosquitoes have the advantage in reducing resistance issue and also environmentfriendly. The disease can be easily controlled by controlling the vectors (e.g. parasitic vectors). The insect population can be reduced by controlling the mosquito larvae which is a result reduce disease burden (Ghosh et al., 2012). Throughout the world and especially in tropical countries, dengue fever is a measure of health problem. Dengue fever could be controlled by reducing Aedes aegypti production (Raveen et al., 2014). It is evident from the result that various concentrations of Sterculia diversifolia stem bark and leaf were the main cause of mortality in A. aegypti larvae as reported from plants Citrus grandis and Tinosphora rhumpii (Gutierrez et al., 2014) $)^{1}$.

Leishmaniasis, a common disease in the subtropical and tropical regions of the world, is an infection of the protozoal parasite of genus Leishmania (Monzote et al., 2014). Currently leishmaniasis is considered as a serious disease due to lack of availability of specific treatment; 
still some semi synthetic and synthetic drugs are implicated to treat leishmaniasis (Mears et al., 2015; Tiuman et al., 2011; Zucca et al., 2013). Drugs such as amphotericin B and pentamidine are also used in the management of leishmaniasis, lacking the desired efficacy (Aronson et al., 2016; Cunha et al., 2015; Sadeghi-Nejad et al., 2011). The extracts Achillea biebersteinii showed promising activity with potent leishmanicidal activities as compared to Sterculia diversifolia stem bark and leaf, which showed mild activity (Al -Sokari et al., 2015).

Insects control relies heavily on the use of synthetic insecticides; however, their widespread use has led to various problems such as the development of insect strains resistant to insecticides (Zia-Ul-Haq et al., 2012). The plant produces various secondary metabolites for defense purposes. These secondary metabolites protect as well as repel the harmful insects to control pests Pavela, 2016; Dubey et al., 2008). Monoterpenes, sesquiterpenes lactones and triterpenes are some of the secondary metabolites of various plants that possess insecticidal activity (Barney et al., 2005; Cespedes et al., 2015; Sosa and Tonn, 2008). Crude extracts of Lepidium sativum and Ipomoea hederacea showed the highest insecticidal activity against all three insects as compare to Sterculia diversifolia (Zia-Ul-Haq et al., 2012). Sterculia diversifolia stem bark, $n$-hexane fraction showed mild to moderate activity against all insects, while the MESD and n-hexane fraction of leaf showed highest activity against Rhyzopertha dominica and Callosobruchus analis respectively.

The anthelmintic potential of tested extract may be due to the presence of similar phytoconstitutes, which was evident. Studies have shown that phenolic and tannin possess plants to produce anthelmintic activities because tannins chemically belong to polyphenolic compounds. Phenolic and tannins are known to interfere with the generation of energy in helminth parasites by uncoup-ling the oxidative phosphorylation and also bind to free proteins in GIT of host animal or glycoprotein on the parasite cuticle, leading to death (Mali and Wadekar, 2008). It is possible that phenolic compounds and tannins also possessing in Sterculia diversifolia stem bark and leaf extracts may be responsible for the anthelmintic activity. Sterculia diversifolia stem bark and leaf shown moderate anthelmintic activity comparable to other medicinal plants e.g. Blumea lacera (Pattewar et al., 2012).

S. diversifolia stem bark and leaf possess various types of phytochemical constituents such as alkaloids, saponins, flavonoids, steroids, tannins etc. These constituents may carry larvicidal, leishmanicidal, insecticidal and anthelmintic potential, although further phytochemical screening is needed. Crude extracts require preliminary screening because it is a complex mixture of bioactive compounds. Hence, these plant extracts are an economical, safe, effective and environment-friendly alternative.

\section{Conclusion}

S. diversifolia stem bark and leaf possess larvicidal, leishmanicidal, insecticidal and anthelmintic agents.

\section{Conflict of Interest}

The authors declare that there is no conflict of interest.

\section{Acknowledgement}

We express our gratitude to Department of Pharmacy, University of Peshawar, Pakistan for providing us research facility. Further we also like to extend our gratitude to HEJ Research Institute of Chemistry, International Centre for Chemical and Biological Sciences, University of Karachi, Karachi, Pakistan.

\section{References}

Alam MR, Raton M, Hassan MM, Kadir MF, Islam SMA, Haque MA. Anthelmintic and diuretic activity of bark extracts of Sterculia villosa. J Appl Pharm Sci. 2012; 2: 86-89.

Ali Q, Gulzar A, Hussain A, Asghar A, Irshad M, Bajwa IU. In vitro antileishmanial and antiglycation evaluation of biphenyl analogues. Sci Int. 2016; 28: 3049-51.

Al-Sokari SS, Ali NA, Monzote L, Al-Fatimi MA. Evaluation of antileishmanial activity of Albaha medicinal plants against Leishmania amazonensis. Bio Med Res Int. 2015; 2015.

Anees AM. Larvicidal activity of Ocimum sanctum Linn. (Labiatae) against Aedes aegypti (L.) and Culex quinquefasciatus (Say). Parasitol Res. 2008; 103: 1451-53.

Aronson N, Herwaldt BL, Libman M, Pearson R, Lopez-Velez R, Weina P, Carvalho EM, Ephros M, Jeronimo S, Magill A. Diagnosis and treatment of leishmaniasis: Clinical practice guidelines by the Infectious Diseases Society of America (IDSA) and the American Society of Tropical Medicine and Hygiene (ASTMH). Clin Infect Dis. 2016; 63: 1539-57.

Barney JN, Hay AG, Weston LA. Isolation and characterization of allelopathic volatiles from mugwort (Artemisia vulgaris). J Chem Ecol. 2005; 31: 247-65.

Bouabdallah S, Laouini D, Bouzouita N, El-Bok S, Sghaier R, Selmi S, Attia M. Separation and evaluation of natural antileishmanial potential against Leishmania major and infuntum isolated from the Tunisia strains. Bangladesh J Pharmacol. 2018; 13: 74-81

Bucker A, Falcao-Bucker NC, Nunez CV, de Souza Pinheiro CC, Tadei WP. Evaluation of larvicidal activity and brine shrimp toxicity of rhizome extracts of Zingiber zerumbet (L.) Smith. Rev Soc Bras Med Trop. 2013; 46: 377-80.

Céspedes CL, Alarcon JE, Aqueveque P, Seigler DS, Kubo I. In 
the search for new secondary metabolites with biopesticidal properties. Isr J Plant Sci. 2015; 62: 216-28.

Cunha MA, Leão AC, de Cassia Soler R, Lindoso JAL. Efficacy and safety of liposomal amphotericin B for the treatment of mucosal leishmaniasis from the new world: A retrospective study. Am J Trop Med Hyg. 2015; 93: 1214-18.

Dubey NK, Srivastava B, Kumar A. Current status of plant products as botanical pesticides in storage pest management. J Biopesticides. 2008; 1: 182-86.

Ghosh A, Chowdhury N, Chandra G. Plant extracts as potential mosquito larvicides. Indian J Med Res. 2012; 135: 581-98.

Gutierrez PM, Aubrey N, Antepuesto, Bryle AL, Eugenio, Maria F, Santos L. Larvicidal activity of selected plant extracts against the dengue vector Aedes aegypti mosquito. Int Res J Biol Sci. 2014; 3: 23-32.

Hosseinzadeh S, Ghalesefidi MJ, Azami M, Mohaghegh MA, Hejazi SH, Ghomashlooyan M. In vitro and in vivo anthelmintic activity of seed extract of Coriandrum sativum compared to niclosamid against Hymenolepis nana infection. J Parasit Dis. 2016; 40: 1307-10.

Khatiashvili NS, Gogilashvili LN, Yarosh EA, Kemertelidze EP. Lipids from Sterculia platanifolia and Hamamelis virginiana seeds. Chem Nat Compd. 2007; 43: 315-16.

Mali RG, Wadekar RR. In vitro anthelmintic activity of Baliospermum montanum muell. Arg roots. Indian J Pharm Sci. 2008; 70: 131-33.

Mears ER, Modabber F, Don R, Johnson GE. A review: The current in vivo models for the discovery and utility of new anti-leishmanial drugs targeting cutaneous leishmaniasis. PLoS Negl Trop Dis. 2015; 9: e0003889.

Monzote L, Piñón A, Setzer WN. Antileishmanial potential of tropical rainforest plant extracts. Medicines 2014; 1: 32-55.

Nisar M, Tariq SA, Marwat IK, Shah MR, Khan IA. Antibacterial, antifungal, insecticidal, cytotoxicity and phytotoxicity studies on Indigofera gerardiana. J Enzyme Inhib Med Chem. 2009; 24: 224-29.

Ouédraogo M, Konate K, Zerbo P, Barro N, Sawadogo LL. Phytochemical analysis and in vitro antifungal profile of bioactive fractions from Sterculia setigera (Sterculiaceae). Curr Res J Biol Sci. 2013; 5: 75-80.

Panda SK, Das D, Tripthathy NK. Phytochemical investigation and anthelmintic activity of various leaf extracts of crotalaria pallida aiton. World J Pharm Pharm Sci. 2015; 4: 336-42.

Pattewar AM, Dawalbajea AB, Gundalea DM, Pawarb PB, Kavtikwara PG, Yerawara PP, Pandharkara TM, Patawar VA. Phytochemistryical and anthelmintic studies on Blumea lacera. Indo Global J Pharm Sci. 2012; 2: 390-96.

Pavela R. History, presence and perspective of using plant extracts as commercial botanical insecticides and farm products for protection against insects: A review. Plant Protect Sci. 2016; 52: 229-41.

Rabbi F, Zada A, Adhikari A, Jabeen A, Nisar A, Ullah I. Sterculia diversifolia bears anti-cancer and immunomodulatory activities. Bangladesh J Pharmacol. 2017; 12: 51-55.

Rahuman AA, Gopalakrishnan G, Venkatesan P, Geetha K, Bagavan A. Mosquito larvicidal activity of isolated compounds from the rhizome of Zingiber officinale. Phytother Res. 2008; 22: 1035-39.

Raveen R, Kamakshi KT, Deepa M, Arivoli S, Tennyson S. Larvicidal activity of Nerium oleander L. (Apocynaceae) flower extracts against Culex quinquefasciatus Say (Diptera: Culicidae). Int J Mosq Res. 2014; 1: 38-42.

Rizwan K, Khan SA, Ahmad I, Rasool N, Ibrahim M, Zubair M, Jaafar HZ, Manea R. A Comprehensive review on chemical and pharmacological potential of Viola betonicifolia: A plant with multiple benefits. Molecules 2019; 24: 3138.

Sadeghi-Nejad B, Saki J, Khademvatan S, Nanaei S. In vitro antileishmanial activity of the medicinal plant- Satureja khuzestanica Jamzad. J Med Plants Res. 2011; 5: 5912-15.

Saeed M, Khan H, Khan MA, Simjee SU, Muhammad N, Khan SA. Phytotoxic, insecticidal and leishmanicidal activities of aerial parts of Polygonatum verticillatum. Afr J Biotechnol. 2010; 9: 1241-44.

Salem MZM, Ali HM, Mansour MM. Fatty acid methyl esters from air-dried wood, bark, and leaves of Brachychiton diversifolius R. Br: Antibacterial, antifungal, and antioxidant activities. Bio Resources. 2014; 9: 3835-45.

Sasikumar K, Ghosh A. Larvicidal activity of prenyl xanthones from Garcinia mangostana against dengue vector. Bangladesh J Pharmacol. 2017; 12: 282-83.

Sosa ME, Tonn CE. Plant secondary metabolites from Argentinean semiarid lands: Bioactivity against insects. Phytochem Rev. 2008; 7: 3-24.

Tiuman TS, Santos AO, Ueda-Nakamura T, Dias Filho BP, Nakamura CV. Recent advances in leishmaniasis treatment. Int J Infect Dis. 2011; 15: e525-32.

Zia-Ul-Haq M, Shah MR, Qayum M, Ercisli S. Biological screening of selected flora of Pakistan. Biol Res. 2012; 45: 375 -79 .

Zucca M, Scutera S, Savoia D. New chemotherapeutic strategies against malaria, leishmaniasis and trypanosomiases. Curr Med Chem. 2013; 20: 502-26. 